\title{
Difluoro-substituted bicyclo[1.1.1]pentanes as novel motifs for medicinal chemistry: design, synthesis and characterization
}

\author{
Roman M. Bychek, ${ }^{\dagger}$ V. Hutskalova ${ }^{\dagger, \#}$ Julia P. Bas,, Olga A. Zaporozhets, ${ }^{\#}$ Sergey Zozulia, ${ }^{\dagger, \S}$ Vadym V. \\ Levterov, ${ }^{\dagger}$ and Pavel K. Mykhailiuk ${ }^{\dagger, \# *}$ \\ ${ }^{\dagger}$ Enamine Ltd., Chervonotkatska 78, 02094, Kyiv (Ukraine), www.enamine.net \\ \#Taras Shevchenko National University of Kyiv, Chemistry Department, Volodymyrska 64, 01601, Kyiv (Ukraine), \\ www.mykhailiukchem.org
}

${ }^{\S}$ Bienta, Chervonotkatska 78, Kyiv 02094 (Ukraine), www.bienta.net

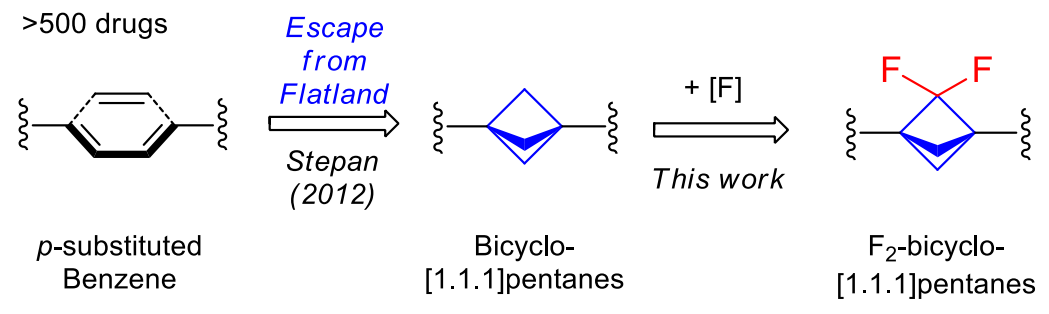

\begin{abstract}
Herein we developed a practical synthetic approach to the previously unknown difluoro-substituted bicyclo[1.1.1]pentanes. The key step was an addition of difluorocarbene to electron-rich bicyclo[1.1.0]butanes by $\mathrm{CF}_{3} \mathrm{TMS}_{\mathrm{N}} \mathrm{NaI}$ system. The obtained difluoro-bicyclo[1.1.1]pentanes are a new generation of saturated bioisosteres of the benzene ring for drug discovery projects.
\end{abstract}

\section{INTRODUCTION}

Benzene ring if one of the most popular fragments in bioactive compounds. ${ }^{1}$ In fact, more than 500 FDA-approved drugs are benzene-containing molecules. ${ }^{2}$ In the context of the recently emerged concept Escape from Flatland ${ }^{3}$ scientists nowadays often replace benzene rings with the saturated bioisosteres ${ }^{4}$ aiming to obtain the patent-free molecules with an improved biological activity and physico-chemical profile. In particular, in 2012 Stepan and colleagues replaced a phenyl moiety in a $\mathrm{\gamma}$-secretase inhibitor with a bicyclo[1.1.1]pentyl skeleton. The obtained analogue showed higher activity, solubility and metabolic stability. ${ }^{5}$ Moreover, the bicyclo[1.1.1]pentyl-containing compound was patent-free, showing a precedent on overcoming patents of pharmaceutical companies on benzene-containing bioactive molecules. Since that moment, bicyclo[1.1.1]pentyl-containing derivatives have been flourishing in chemistry: they are already mentioned in $>100$ patents by academic groups and commercial companies (Figure 1). ${ }^{6}$
An increasing demand from pharmaceutical institutions, initiated many academic research projects aimed at elaboration of novel synthetic approaches to bicyclo[1.1.1]pentylsubstituted building blocks. Most of the work in this area is devoted to the synthesis of mono- and 1,3-disubstituted derivatives. $^{7-9}$ At the same time, however, dreams about the new generation of bicyclo[1.1.1]pentanes with a 2-substitution at the side chain are frequently discussed at scientific conferences on medicinal chemistry. Such structures, in turn, would give access into novel 3D-shaped chemical space, and will additionally provide with an opportunity to mimic the ortho-substituted benzenes. Although several bridgesubstituted propellanes are known, ${ }^{10}$ they are obtained through multistep synthetic procedures often employing gaseous reagents and photochemical transformations. It is important to mention that 2,2-dichloro[1.1.1]propellane was reported, but was unstable. ${ }^{11}$ This suggests that other propellanes with the bridge substituents which can act as leaving groups - fluorine, oxygen, sulphur - might be also unstable. As a result, the 
bicyclo[1.1.1]pentanes with the substitution at the bridge positions are very rare. ${ }^{12}$ Not surprising that over the years, many pharma-companies initiated internal research projects trying to access these structures; with no success so far, however.

Herein, we present our studies towards the preparation of difluoro-substituted at the bridge position bicyclo[1.1.1]pentanes - a class of compounds unknown before (Figure 1).
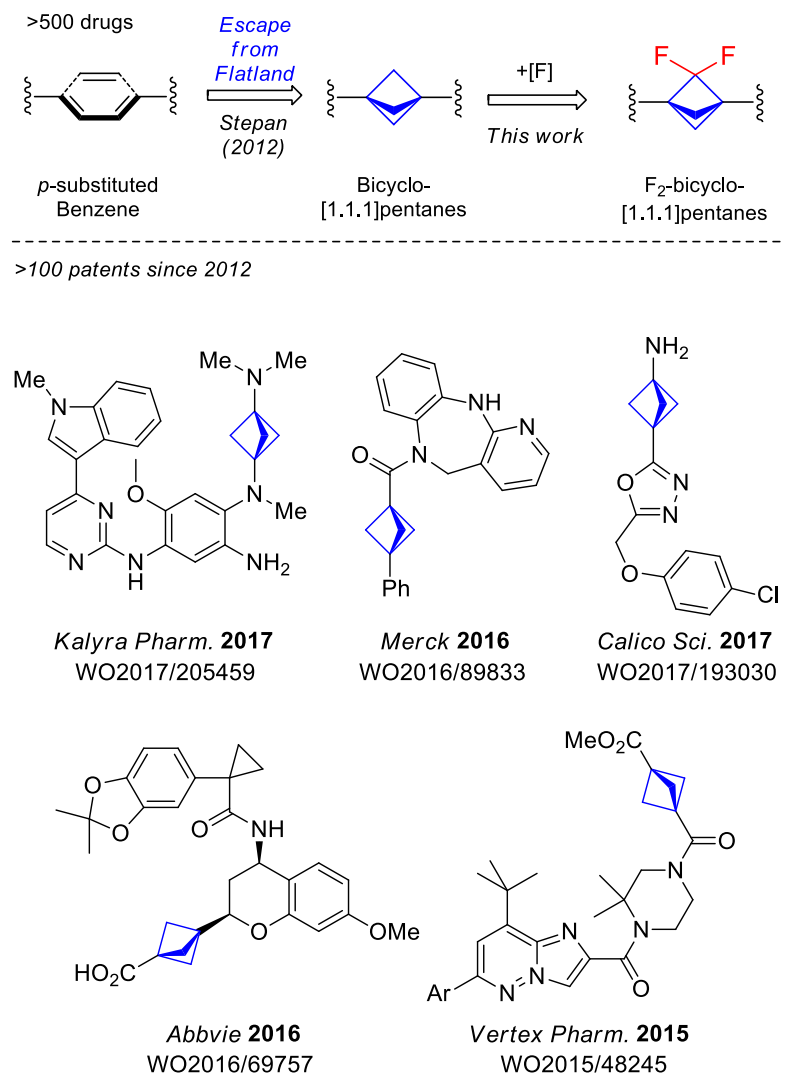

Figure 1. Application of bicyclo[1.1.1]pentanes in medicinal chemistry. Objectives of this work: side-chain fluorinated bicyclo[1.1.1]pentanes.

\section{RESULT AND DISCUSSION}

1) Attempted directed CH-fluorination. In 2015, Xu and coworkers described palladium-catalyzed $\mathrm{CH}$-fluorination of aliphatic amides of 8 -aminoquinoline. ${ }^{13}$ Therefore, we first tried to extend this reaction to bicyclo[1.1.1]pentane core. Reaction of acid $\mathbf{1}$ with 8-aminoquinoline using carbonyldiimidazole EDC as an amide-coupling reagent in dichloromethane as a solvent smoothly gave the needed amide 2 in $71 \%$ yield (Scheme 1). Unfortunately, all our attempts to perform directed $\mathrm{CH}$-fluorination of compound $\mathbf{2}$ following either reported or modified conditions failed. Increasing the reaction temperature and time only led to decomposition of the starting compound. Presumably, compound $\mathbf{2}$ was too rigid to adopt the proper conformation for the $\mathrm{CH}$-activation.
Previously, we observed similar effect, as several conformationally restricted analogues of proline did not react under the standard directed $\mathrm{CH}$-arylation conditions. ${ }^{14}$

In 2016, Hrdina and colleagues showed that for the conformationally rigid 1-adamantane-carboxylic acid, 8 -aminoquinoline was ineffective directing group in $\mathrm{Pd}$-catalyzed $\mathrm{CH}$-arylation reactions. The authors also found that the more flexible 2-aminomethyl pyridine worked well in this role. ${ }^{15}$ We wanted to take advantage of this discovery and to provide our model substrate even with more flexibility: we took a homologue of acid $\mathbf{1}$ - acid $\mathbf{4}$ having one additional methylene group (Scheme 1). Reaction of acid 4 with 2-aminomethyl pyridine in the presence of EDC as a condensing reagent in dichloromethane afforded the target model amide 5 in $82 \%$ yield. Similar to amide 2, however, all our efforts to perform $\mathrm{Pd}$-catalyzed $\mathrm{CH}$-fluorination of compound 5 were unsuccessful. We did not observe the formation of the required product under all conditions we tried. Again, prolongation of the reaction time and increasing temperature only led to a decomposition of the starting material.

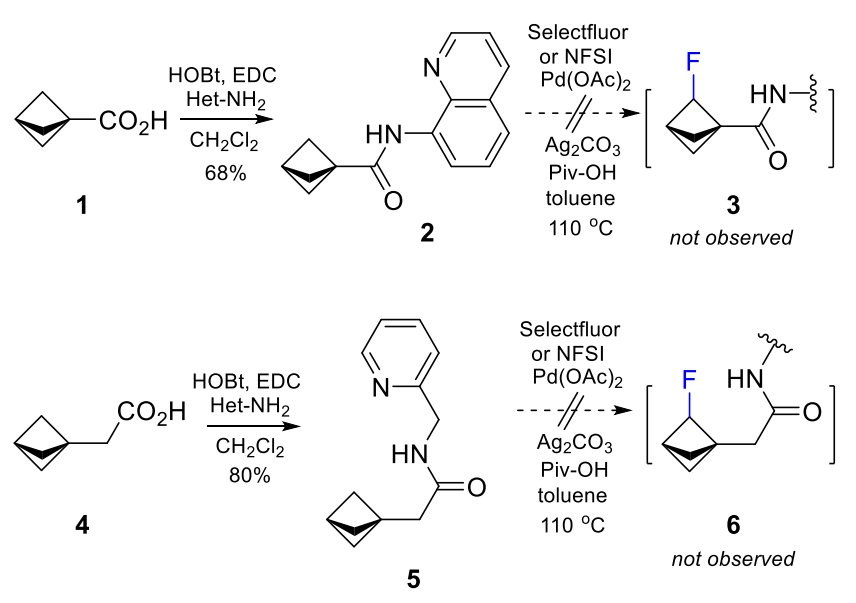

Scheme 1. Attempted Pd-catalyzed directed $\mathrm{CH}$-fluorination of bicyclo[1.1.1]pentanes $\mathbf{2}$ and $\mathbf{5}$.

Worth mentioning, that substrates $\mathbf{2}$ and $\mathbf{5}$ also failed to give any arylation product with $\mathrm{PhI}$ under the previously developed conditions. ${ }^{14,16}$ At this point we decided to stop working in this direction and concentrated our efforts onto another approach - electrochemical fluorination.

2) Attempted electrochemical $\mathbf{C H}$-fluorination. There are several precedents in the literature on the direct functionalization of bicyclo[1.1.1]dicarboxylate (7) with chlorine and fluorine gases. For example, in 1989, Robinson and Michl reported on the direct chlorination of diacid 7 with chlorine gas under irradiation. ${ }^{17}$ The selectivity of the reaction was achieved by careful control of the reaction temperature and time. The reaction with molecular bromine or iodine did not take place. In 1997, the same group treated diacid 7 with 
fluorine gas: the reaction was unselective, however, giving a complex mixture of polyfluorinated derivatives. ${ }^{18}$ On the other hand, recently Baran and coworkers developed a practical electrochemical $\mathrm{CH}$-fluorination protocol of aliphatic compounds. ${ }^{19}$ Being involved in this project, we wanted next to expend this methodology onto diacid 7. In fact, a dilute solution of compound 7, Selectfluor and mediator $\mathrm{NaNO}_{2}$ in acetonitrile was electrolyzed under a constant current of $3 \mathrm{~mA}$ during different periods of time. The consumed charge was varied between 0.1-3.0 F/mol. Unfortunately, we did not observe the formation of the desired product $-{ }^{19} \mathrm{~F}-\mathrm{NMR}$ of the reaction mixture showed no needed signals (Scheme 2). Over the time, only slow decomposition of the starting material took place.

Failure in both $\mathrm{CH}$-activation and electrochemical fluorination prompted us to focus on the third strategy of the synthesis of fluorinated bicyclo[1.1.1]pentanes.

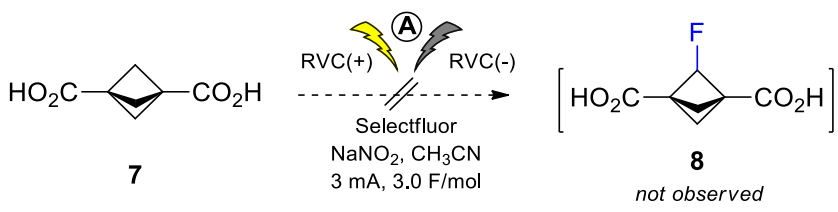

Scheme 2. Attempted electrochemical fluorination of diacid 7.

3) Addition of difluorocarbene to bicyclo[1.1.0]butanes. There are several precedents in the literature on the addition of dibromocarbene $\left(: \mathrm{CBr}_{2}\right)$ and dichlorocarbene $\left(: \mathrm{CCl}_{2}\right)$ to bicyclo[1.1.0]butanes to form the dihalosubstituted bicyclo[1.1.1]pentaines in $16-48 \%$ yields. ${ }^{20}$ Mechanistically, this reaction represents an analogy to the cyclopropanation of alkenes, where a p-rich central bond of bicyclo[1.1.0]butane reacts with electrophilic dibromo- or dichlorocarbenes. Keeping this in mind, we wondered whether the same transformation could occur with $\left(: \mathrm{CF}_{2}\right)$. Due to the even higher electrophilicity of difluorocarbene compared with $: \mathrm{CCl}_{2}$ and $: \mathrm{CBr}_{2}$, we expected that this reaction would be feasible, and even expected the higher yields of products. There were no examples in the literature on that transformation, however. First, we synthesized a model compound 9 following the experimental procedure published in a patent literature (Scheme 3). ${ }^{21}$ The commercially available and relatively cheap acid 10 (25 g / 60 \$) was treated with $\mathrm{PhMgCl}$ in tetrahydrofurane at room temperature to afford alcohol $\mathbf{1 1}$ as a mixture of two stereoisomers. Reaction of the latter with concentrated aqueous hydrochloric acid in toluene gave the chloride 12. Carboxylic function in $\mathbf{1 2}$ was alkylated with $\mathrm{MeI}$ in dimethylformamide using potassium carbonate as a base. Ester 13 was obtained by column chromatography in 83\% isolated yield over three steps starting from acid $\mathbf{1 0 .}$ Cyclization of compound 13 with NaHMDS gave the needed model substrate $\mathbf{9}$ in $71 \%$ yield.

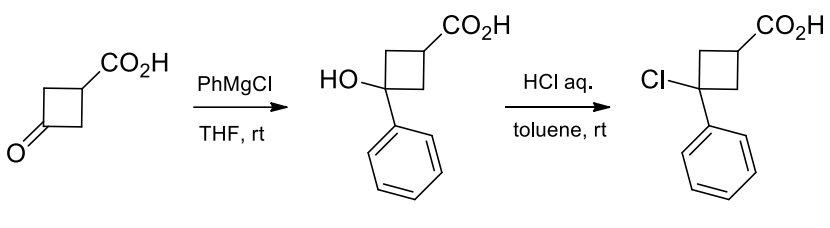

10

11

12

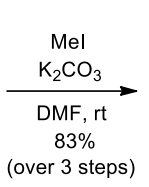

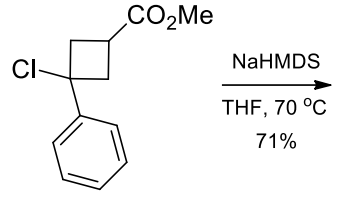

13

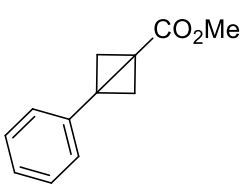

9
Scheme 3. Synthesis of the starting substrate 9.

Finally, we studied an addition of difluorocarbene to bicyclo[1.1.0]butane 9 (Table 1). First, we tried the oldest, and certainly one of the cheapest reagents - sodium chlorodifluoroacetate, - that we successfully used for the difluorocyclopropanation of various alkenes previously. ${ }^{22}$ Indeed, we observed the formation of product 14 , but in low yields (Table 1, entries 1-3). The use of $\mathrm{Hg}\left(\mathrm{CF}_{3}\right)_{2}$ or Dolbier reagent - $\mathrm{FSO}_{2} \mathrm{CF}_{2} \mathrm{CO}_{2}$ TMS (TFDA) did provide the product in up to $50 \%$ yield (Table 1, entries 4-7). Finally, we studied the system $\mathrm{CF}_{3} \mathrm{TMS} / \mathrm{NaI}$ that was used before for the difluorocyclopropanation of various functionalized alkenes. ${ }^{23}$ The reaction already efficiently proceeded with 3 eq. of $\mathrm{CF}_{3} \mathrm{MTS}$, but increasing its amount to 10 equiv allowed the isolation of the difluoro-compound $\mathbf{1 4}$ in $68 \%$ yield (Table 1, entries 8-11). The use of larger excess of $\mathrm{CF}_{3} \mathrm{TMS}$, modifying amount of $\mathrm{NaI}$ or using other solvents did not give any further boost in yield (Table 1, entries 11-15). For further studies on small scale we used ten equivalents of $\mathrm{CF}_{3} \mathrm{TMS}$, but for the subsequent multigram synthesis, this amount could be safely reduced to two-three equivalents.

It is worth mentioning that even under the optimized conditions, we also isolated a side product $\mathbf{1 5}$ in $19 \%$ yield from a reaction mixture (Scheme 4). Compounds of this type are usually formed as the main products in the reaction bicyclo[1.1.0]butanes with carbene obtained by photolysis of diazomethane, ${ }^{24}$ or with metal-carbenoids under the SimmonsSmith conditions. ${ }^{25}$ Formation of bicyclo[1.1.1]pentanes was never observed in those reactions. With more electrophilic dibromo- and dichlorocarbenes, bicyclo[1.1.1]pentanes were formed, but only as minor components, whereby dienes of type 15 prevailed. ${ }^{20 a, b}$ The highly electrophilic nature of difluorocarbene seems to switch the reactivity of bicyclo[1.1.0]butanes, as the bicyclo[1.1.1]pentane $\mathbf{1 4}$ is formed as a main reaction product, while compound $\mathbf{1 5}$ - as a minor side product. 
Table 1. Optimization of the reaction conditions.

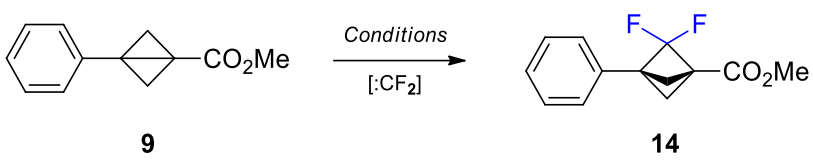

\begin{tabular}{|c|c|c|c|c|c|}
\hline Entry $^{\mathrm{a}}$ & Reagent & Solvent & Addit. & $\mathrm{T}\left({ }^{\circ} \mathrm{C}\right)^{\mathrm{b}}$ & Yield $(\%)^{\mathrm{c}}$ \\
\hline 1 & $\mathrm{CF}_{2} \mathrm{ClCO}_{2} \mathrm{Na}$ (3 eq.) & toluene & & 110 & 12 \\
\hline 2 & $\mathrm{CF}_{2} \mathrm{ClCO}_{2} \mathrm{Na}$ (5 eq.) & xylene & & 150 & 16 \\
\hline 3 & $\mathrm{CF}_{2} \mathrm{ClCO}_{2} \mathrm{Na}$ (10 eq.) & glyme & & 170 & 23 \\
\hline 4 & TFDA (3 eq.) & toluene & $\mathrm{LiF}(5 \%)$ & 110 & 32 \\
\hline 5 & TFDA (5 eq.) & toluene & $\operatorname{LiF}(10 \%)$ & 110 & 44 \\
\hline 6 & TFDA (10 eq.) & toluene & $\mathrm{LiF}(20 \%)$ & 110 & 51 \\
\hline 7 & $\left(\mathrm{CF}_{3}\right)_{2} \mathrm{Hg}$ (2 eq. $)$ & THF & $\mathrm{NaI}(200 \%)$ & 70 & 21 \\
\hline 8 & $\mathrm{CF}_{3} \mathrm{TMS}$ (1 eq.) & THF & $\mathrm{NaI}(20 \%)$ & 70 & 44 \\
\hline 9 & $\mathrm{CF}_{3} \mathrm{TMS}$ (3 eq.) & THF & $\mathrm{NaI}(20 \%)$ & 70 & 61 \\
\hline 10 & $\mathrm{CF}_{3} \mathrm{TMS}$ (5 eq.) & THF & $\mathrm{NaI}(20 \%)$ & 70 & 66 \\
\hline 11 & $\mathrm{CF}_{3} \mathrm{TMS}$ (10 eq.) & THF & $\mathrm{NaI}(20 \%)$ & 70 & $73(68)^{d}$ \\
\hline 12 & $\mathrm{CF}_{3}$ TMS (20 eq.) & THF & $\mathrm{NaI}(20 \%)$ & 70 & 71 \\
\hline 13 & $\mathrm{CF}_{3} \mathrm{TMS}$ (10 eq.) & THF & $\mathrm{NaI}(40 \%)$ & 70 & 70 \\
\hline 14 & $\mathrm{CF}_{3}$ TMS (10 eq.) & THF & $\mathrm{NaI}(10 \%)$ & 70 & 72 \\
\hline 15 & $\mathrm{CF}_{3} \mathrm{TMS}$ (10 eq.) & $\mathrm{CH}_{3} \mathrm{CN}$ & $\mathrm{NaI}(20 \%)$ & 70 & 62 \\
\hline
\end{tabular}

Mechanistically, it seems reasonable to assume that the central $p$-rich bond in compound 9 attacks the electrophilic : $\mathrm{CF}_{2}$ to form a stable benzylic carbocation $\mathbf{A}$. The rearrangement of the latter gives a putative alkene $\mathbf{1 6}$ (Scheme 4). Although we did not isolate alkene $\mathbf{1 6}$ in the individual state, we did observe in ${ }^{1} \mathrm{H}$ NMR of the reaction mixture the formation of characteristic alkene protons at 5.5-6.0 ppm that disappeared over the time in a course of the reaction. Indeed, styrene $\mathbf{1 6}$ rapidly reacted with an excess of difluorocarene to give the side product $\mathbf{1 5}$. Acrylic double bond in $\mathbf{1 5}$ is far less reactive towards difluorocarbene, however, upon prolonged reaction times we did also observe its slow difluorocyclopropanation.
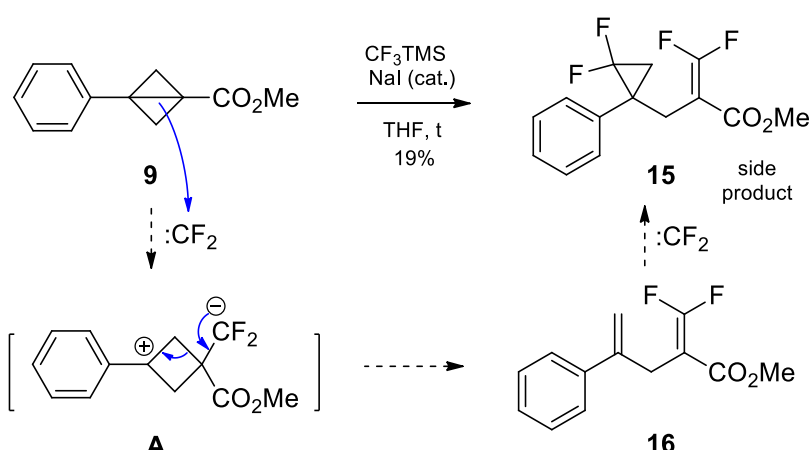

observed in ${ }^{1} \mathrm{H}$ NMR of r.m.

Scheme 4. Proposed mechanism for the formation of the side product 15.

Hydrolysis of the ester group in compound $\mathbf{9}$ smoothly gave acid $\mathbf{1 7}$ which is a valuable building block for medicinal chemistry projects (Scheme 5). Next, we challenged its gramscale synthesis. The only modification to the previously elaborated procedure was the amount of $\mathrm{CF}_{3} \mathrm{TMS}$ in the addition of difluorocarbene. To reduce the costs of the synthesis, we decreased an excess of $\mathrm{CF}_{3} \mathrm{TMS}$ from 10 equiv. to 3 equiv. This affected the reaction yield, but not dramatically - product $\mathbf{1 4}$ was isolated in $45 \%$ yield. Significant formation of the side product $\mathbf{1 5}$ was also observed. Finally, hydrolysis of the ester group in $\mathbf{1 4}$ gave acid $\mathbf{1 7}$ as a white solid in $7 \mathrm{~g}$ scale.

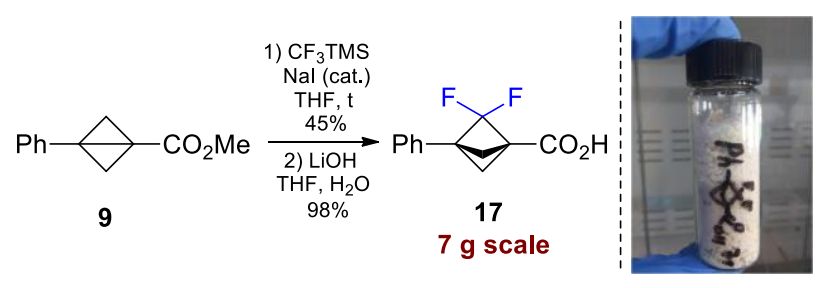

Scheme 5. Gram-scale synthesis of acid 17.

The molecular structure acid $\mathbf{1 7}$ was confirmed by X-Ray analysis (Figure 2).

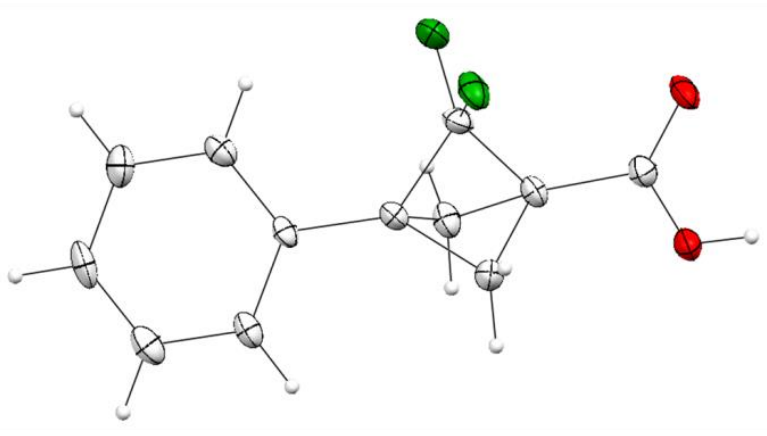

17

Figure 2. $X$-Ray crystal structure of acid 17. Atoms are shown as ellipsoids at $25 \%$ probability level. Atoms of fluorine - green, oxygen - red. ${ }^{26}$

Having elaborated a practical procedure to phenylsubstituted bicyclo[1.1.1]pentane 14, we wanted to understand how sensitive the reaction was to the substituents at the phenyl ring. Although, a detailed scope of this transformation is beyond the scope of this communication, we synthesized two representative key starting compounds bearing either the electron-withdrawing para-fluorine substituent at the phenyl ring (18), or an electron-donating methyl-group (19). The both compounds were easily synthesized in several steps from acid 10 following the previously described strategy (Scheme 3). Compounds 18 and 19 smoothly reacted with $\mathrm{CF}_{3} \mathrm{TMS} / \mathrm{NaI}$ to form the needed fluorinated bicyclo[1.1.1]pentanes $\mathbf{2 0}$ and $\mathbf{2 1}$ (Scheme 6).

The reactivity of substrate $\mathbf{2 2}$ (prepared also from acid 10) towards the difluorocarbene is noteworthy. The reaction 
occurred first selectively at the central bond of bicyclo[1.1.0]butane (Scheme 6). The present $-\mathrm{CH}=\mathrm{CH}_{2}$ double bond started to react only when the reaction of the central bond was finished. Therefore, control of the reaction by TLC and NMR allowed the isolation of the needed vinylsubstituted product $\mathbf{2 3}$ in $60 \%$ yield.

Despite the advantages outlined herein, the developed strategy is not without limitation: the aryl/vinyl-substituents at the bicyclo[1.1.0]butane core were found to be crucial for the formation of bicyclo[1.1.1]pentanes. Unfortunately, none, of the tested substrates 24-26 gave the expected products. In every case, the compounds were unreactive. Increasing the reaction temperature in the external oil bath, and the prolonged reaction time led to the formation of complex mixtures. Some signals corresponding to the alkene fragment in ${ }^{1} \mathrm{H}$ NMR indicated the formation of alkenes of the type $\mathbf{1 6}$ apart from other side products.

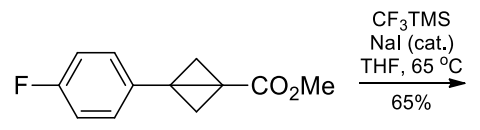

18

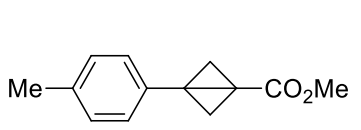

$\mathrm{CF}_{3} \mathrm{TMS}$
$\mathrm{Nal}$ (cat.)
$\underset{\mathrm{THF}, 65^{\circ} \mathrm{C}}{\longrightarrow}$

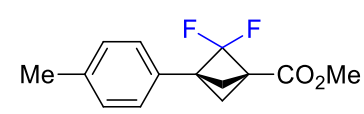

19

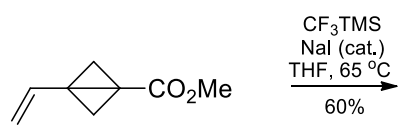

22

Limitations:

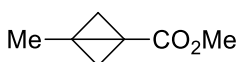

24

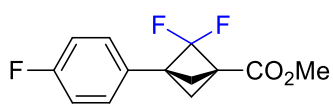

20

21

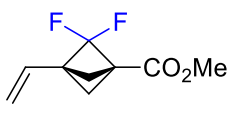

23

26

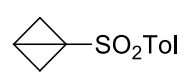

Scheme 6. Synthesis of difluoro-substituted bicyclo[1.1.1]pentanes 21-23. Unreactive substrates 24-26.

Synthesis of building blocks. Next, we performed several representative postmodifications of difluoro-substituted bicyclo[1.1.1]pentanes to obtain the corresponding building blocks for the direct use in drug discovery projects. For example, Curtius rearrangement of acid 17 with $(\mathrm{PhO})_{2} \mathrm{P}(\mathrm{O}) \mathrm{N}_{3}$ in tert-butanol, followed by acidic $N$-Boc deprotection gave amine $\mathbf{2 7}$ in the form of hydrochloride as a white solid (Scheme 7). Reduction of the ester group in $\mathbf{1 4}$ with $\mathrm{LiAlH}_{4}$ in tetrahydrofuran smoothly provided alcohol $\mathbf{2 8}$ in $95 \%$ yield. Hydrolysis of esters 20, 21 and 23 with $\mathrm{LiOH}$ at room temperature gave acids $\mathbf{2 9 - 3 1}$ in 100-300 mg scale.

All previously described difluoro-substituted bicyclo[1.1.1]pentanes contained aryl-substituents. Therefore, we also oxidized the vinyl group in compound 23 with $\mathrm{NaIO}_{4}$ and the catalytic amount of $\mathrm{RuCl}_{3}$ to obtain mono-acid 32 . Compound $\mathbf{3 2}$ opens up a way to synthesize various bifunctional derivatives: amino acids, amines, diamines etc. This tactic is being used routinely these days to synthesize difunctional bicyclo[1.1.1]pentyl derivates from nonfluorinated acid 33 (Scheme 7). 27
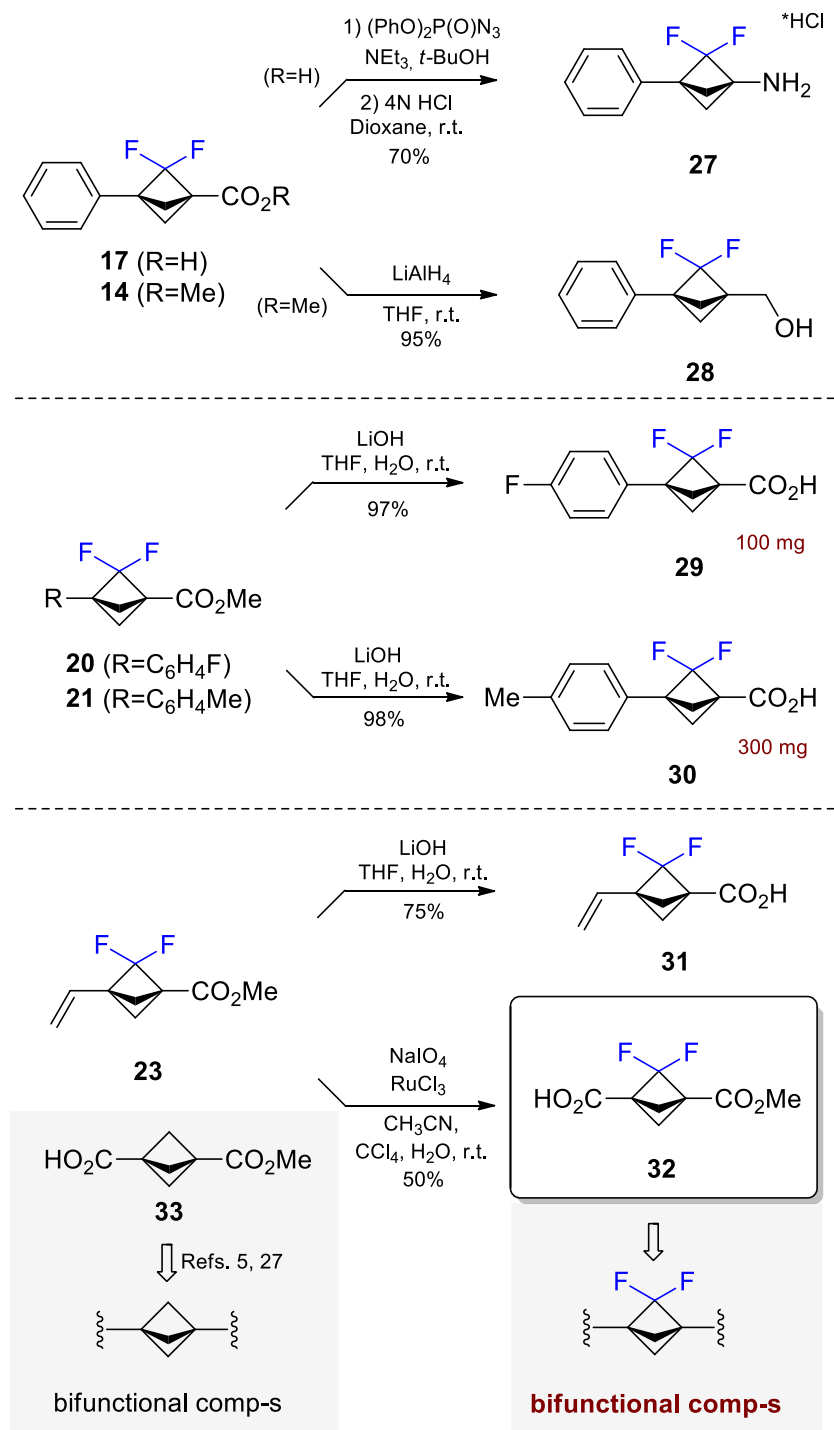

Scheme 7. Synthesis of mono- (27-31) and bifunctional difluoro-substituted bicyclo[1.1.1]pentane $\mathbf{3 2}$.

Chemical stability. Indeed, because the donor-acceptor cyclobutanes sometimes undergo ring-fragmentation, ${ }^{28}$ we next checked a chemical stability of difluorobicyclo[1.1.1]pentaines, being strained cyclobutanes. Luckily, 
treatment of acid $\mathbf{1 7}$ and amine 27 with aq. $1 \mathrm{M}$ hydrochloric acid, or aq. $1 \mathrm{M}$ sodium hydroxide at room temperature for 24 hours did not lead to any decomposition of the starting materials. These experiments indicate that described herein products possess sufficient chemical stability and, indeed, can be used as building blocks in medicinal chemistry.

Crystallographic analysis. In 2011, O'Hagan and coworkers showed that gem-difluorination of cycloalkanes altered significantly their geometry. ${ }^{29}$ We next checked whether incorporation of fluorine atoms would have an effect on the geometry of the bicyclo[1.1.1]pentane skeleton. Luckily, there are two related non-fluorinated compounds $\mathbf{3 4}$ and $\mathbf{3 5}$ reported in the literature with the known crystallography data. ${ }^{30}$ Therefore, we compared geometric parameters of all three molecules 17, 34 and 35 (Table 2). Incorporation of gemdifluoro unit slightly shortened $\mathrm{C}(2)-\mathrm{C}(3)$ and $\mathrm{C}(3)-\mathrm{C}(4)$ bonds: $1.515-1.529 \AA$ (17) vs 1.540-1.560 $\AA$ (34, 35). Also, it increased the internal $\mathrm{C}(2)-\mathrm{C}(3)-\mathrm{C}(4)$ angle: $78.2^{\circ}$ (17) $v s$ $74.5-75.3^{\circ}(\mathbf{3 4}, \mathbf{3 5})$. The factors describing the collinearity of substituents - angles $\gamma_{1}$ and $\gamma_{2}$, - did not deviate significantly from the ideal value of $180^{\circ}: 178.0-179.1^{\circ}$ (17) vs 178.3$179.6^{\circ}(\mathbf{3 4}, \mathbf{3 5})$. The distance between the bridgehead carbon atom $\mathrm{C}(2)-\mathrm{C}(4)$ of the bicyclo[1.1.1]pentane was somewhat elongated: $1.919 \AA$ (17) vs 1.882-1.891 $\AA$ (34, 35).

Table 2. Selected parameters of bicyclo[1.1.1]pentanes 17, 34, 35 according to X-Ray crystal data: bond lengths $(\AA)$, angles $\left(^{\circ}\right)$, and distances $(\AA)$.

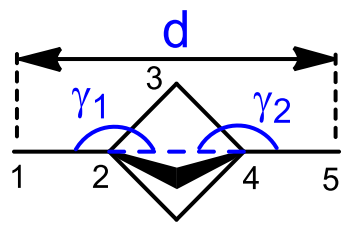

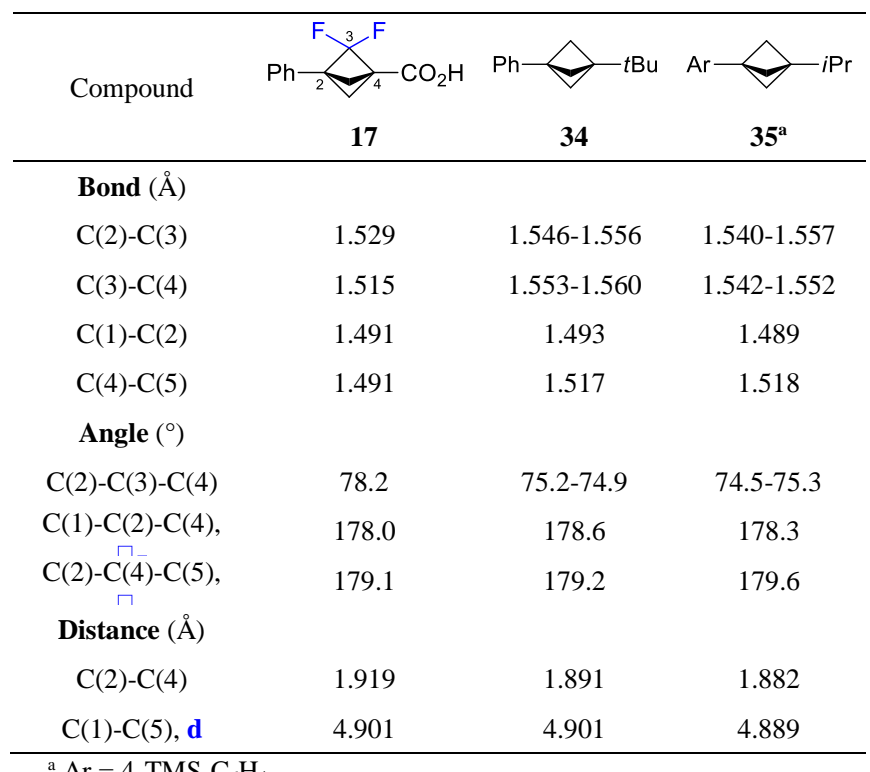

${ }^{\mathrm{a}} \mathrm{Ar}=4-\mathrm{TMS}-\mathrm{C}_{6} \mathrm{H}_{4}$
Importantly, however, that the key parameter, distance between the substituents - d, - was not changed at all: $4.901 \AA$ (17) vs 4.889-4.901 $\AA(\mathbf{3 4}, \mathbf{3 5})$.

In short summary, although gem-difluorination slightly changed some bond lengths and internal angles of the bicyclo[1.1.1]pentane core, it did not affect its key characteristics that are important for medicinal chemistry: overall 3D-shape, collinearity of the substituents $\left(178-179^{\circ}\right)$ and distance between them (4.9 ̊).

Acidity/basicity of functional groups. Incorporation of fluorine atoms into organic molecules changes significantly acidity/basicity of the neighboring functional groups. ${ }^{31}$ For this reason we experimentally measured $\mathrm{p} K_{\mathrm{a}}$ values of acids 17, 35 and amine hydrochlorides 27, 36 (Figure 3). Thus, gemdifluorination of acid 35 increased its acidity by one magnitude of order: $\mathrm{p} K_{\mathrm{a}}(\mathbf{3 5})=4.0 v s \mathrm{p} K_{\mathrm{a}}(\mathbf{1 7})=3.0$. On the other hand, gem-difluorination of amine $\mathbf{3 6}$ reduced its basicity by already three magnitudes of order: $\mathrm{p} K_{\mathrm{a}}(36 * \mathrm{HCl})=$ 7.9 vs $\mathrm{p} K_{\mathrm{a}}(27 * \mathrm{HCl})=4.9$. The much bigger impact of fluorination on the basicity than on the acidity can be explained in terms of - $(I)$-inductive effect of fluorine atoms. In acid 17, fluorine atoms and the acidic hydrogen atom are distanced by five single bonds. At the same time, in amine $\mathbf{2 7}$, fluorine atoms and the basic nitrogen atom are distanced by three single bonds; hence an effect of fluorination on the basicity is bigger.

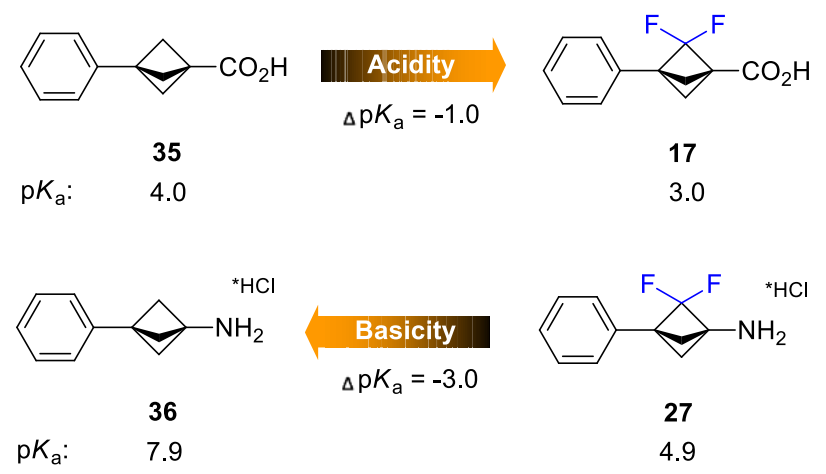

Figure 3. Experimental $\mathrm{p} K_{\mathrm{a}}$ values of acids 17, 35; and conjugated amines $27 * \mathrm{HCl}$ and $36 * \mathrm{HCl}$.

Water solubility and lipophilicity. Fluorination is known also to affect the physico-chemical properties of organic compounds, such as water solubility and lipophilicity. ${ }^{31}$ Therefore, we first synthesized model amides 37-39 (Scheme 8 ) and measured their experimental $\log \mathrm{D}$ and water solubility values.

As it was expected, ${ }^{5,6 a, 32}$ replacement of the benzene ring in compound 37 by bicyclo[1.1.1]pentane increased the water solubility by almost 4-times: 104 uM (37) vs 370 uM (38) (Table 3). Gem-fluorination of compound 38 slightly reduced its water solubility: $370 \mathrm{uM} \mathrm{(38)}$ vs $250 \mathrm{uM}$ (39). Nevertheless, 
the water solubility of gem-difluorinated bicyclo[1.1.1]pentane 39 was almost 2.5-times higher than that of the benzene-containing containing compound 37: $250 \mathrm{uM}$ (39) vs $104 \mathrm{uM} \mathrm{(37).}$

An effect of benzene substitution and fluorination of bicyclo[1.1.1]pentane onto lipophilicity was less profound (Table 3). The replacement of the benzene ring in compound 37 by bicyclo[1.1.1]pentane slightly reduced its lipophilicity, as measured by $\log \mathrm{D}(7.4)$ index: 3.6 (37) vs 3.4 (38). Gemdifluorination of bicyclo[1.1.1]pentane again increased the lipophilicity, $\log \mathrm{D}(7.4)$ : 3.4 (37) vs 3.6 (38).

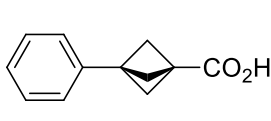

35

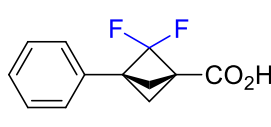

17
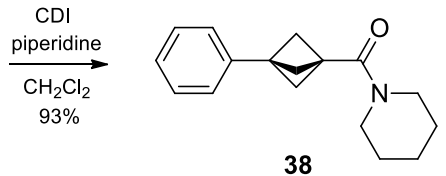

38

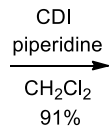

$91 \%$
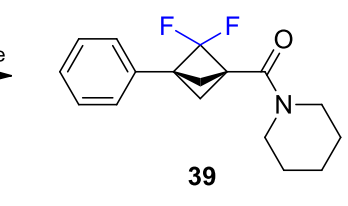

Scheme 8. Synthesis of model amides $\mathbf{3 8}$ and $\mathbf{3 9}$.

Table 3. Experimental lipophilicity and solubility data of model compounds 37-39.

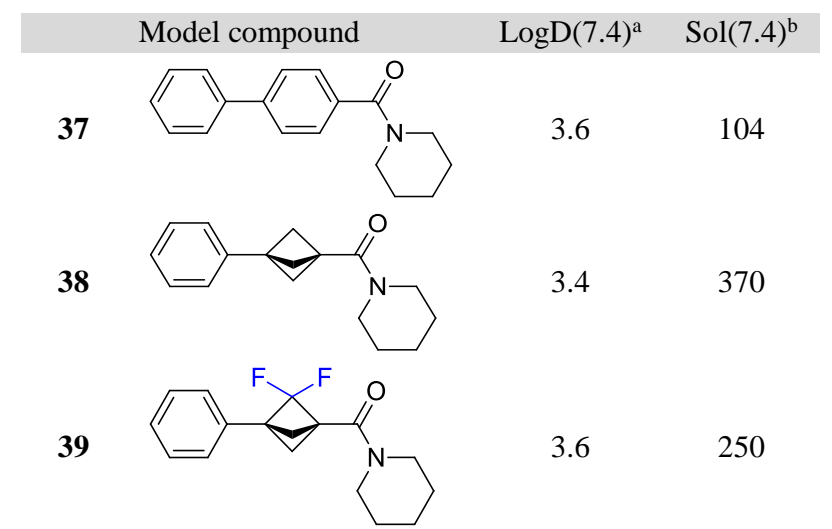

${ }^{\text {a}}$ Experimental $n$-octanol/water distribution coefficient $(\log )$ at $\mathrm{pH} 7.4$;

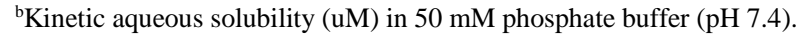

In short summary, gem-difluorination of bicyclo[1.1.1]pentane decreased its water solubility, and slightly reduced lipophilicity $(\log \mathrm{D})$. On the other hand, replacement of the benzene ring (37) with gem-difluoro bicyclo[1.1.1]pentane (39) selectively increased significantly its water solubility and did not affect its lipophilicity, which might be beneficially used in medicinal chemistry programs.

Possible application areas. After a practical synthesis of gem-difluorinated bicyclo[1.1.1]pentanes, and demonstration that their chemical and physico-chemical properties are compatible with medicinal chemistry requirements, we also

wanted to suggest areas, where these building blocks might be useful. Indeed, they can be considered as advanced mimics for the substituted benzene rings, but there are some particular cases that in our opinion are worth mentioning (Scheme 9).

a) C-F benzene (2012, Stepan): ${ }^{5}$

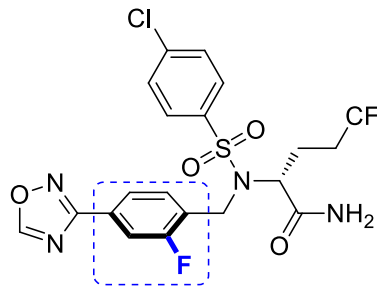

40 (BMS-708,163

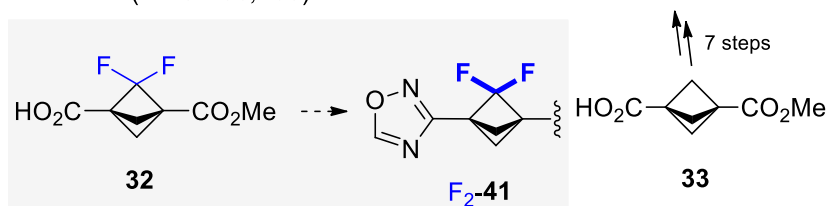

b) $\mathrm{p} K_{\mathrm{a}}$ modulation $(2017$, Adsool): $27 \mathrm{c}$
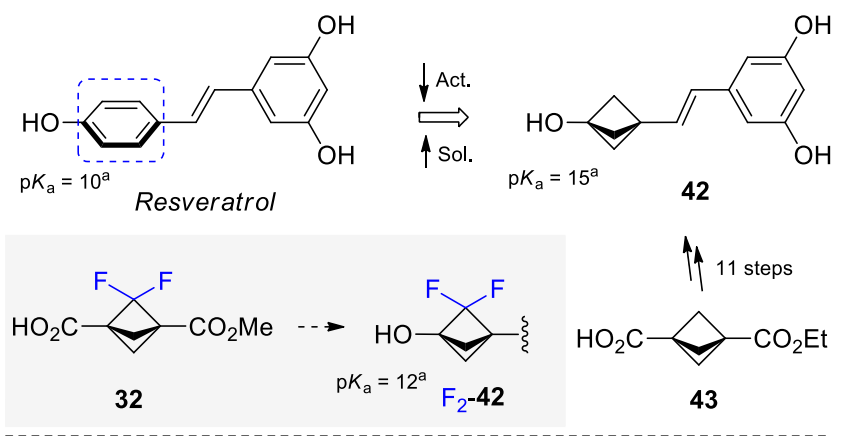

c) Ar-Ar motifs (2017, Measom, Hirst): ${ }^{27 d}$

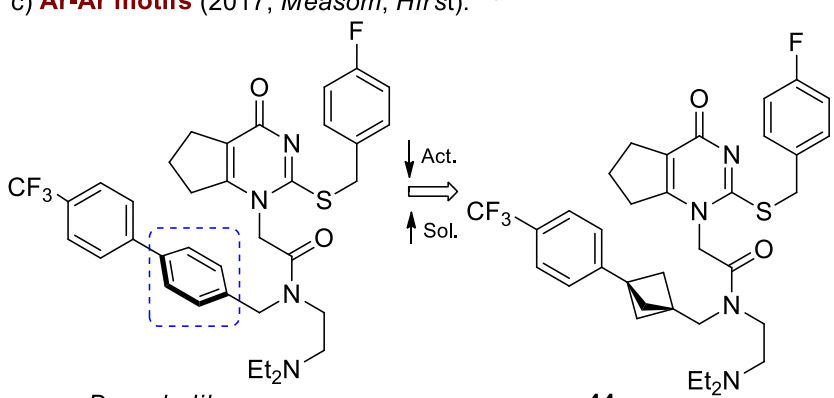

Darapladib

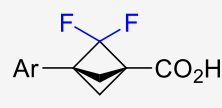

46

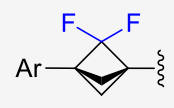

$\mathrm{F}_{2}-44$
44

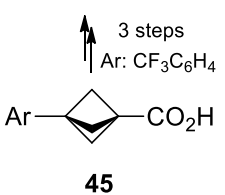

Scheme 9. Possible application areas for gem-difluorinated bicyclo[1.1.1]pentanes. ${ }^{\mathrm{a} C a l c u l a t e d} \mathrm{p} K_{\mathrm{a}}$ values.

For example, in 2012, Stepan and colleagues made an intriguing discovery: the authors replaced a fluorophenyl moiety in the $\mathrm{\gamma}$-secretase inhibitor 40 (BMS-708,163) with a bicyclo[1.1.1]pentyl skeleton to obtain compound 41 (Scheme 
9a). ${ }^{5}$ Synthetically, compound $\mathbf{4 1}$ was obtained from acid $\mathbf{3 3}$ in 7 steps. Compound $\mathbf{4 1}$ showed better activity, and higher solubility than 40. On the other hand, the original compound 40 possessed a fluoro-substituted phenyl ring, and it is strategically reasonable also to test the fluorinated analogues of compound 41, because fluorine atoms are often involved in the specific ligand-protein interactions. ${ }^{33}$ In particular, the synthesis of $\mathrm{F}_{2}-\mathbf{4 1}$ could have been realized from acid $\mathbf{3 2}$ (Scheme 7).

Resveratrol is a natural compound exhibiting anticancer activity (Scheme 9b). In 2017, Adsool and co-workers replaced the phenyl ring in Resveratrol by bicyclo[1.1.1]pentyl skeleton (42). ${ }^{27 c}$ Compound 42 was synthesized in 11 steps from acid 43. Compared to Resveratrol, compound $\mathbf{4 2}$ had 40-times better water solubility and almost identical activity against cancer cells. However, replacement of the aromatic phenol moiety by aliphatic bicyclo[1.1.1]pentan-ol led to decrease in OH-acidity: $\mathrm{p} K_{\mathrm{a}}=10$ (Resveratrol) vs 15 (42). From the strategic standpoint it would have been desirable also to synthesize and test the fluorinated compound $F_{2}-\mathbf{4 2}$ that might have a much closer acidity of the $\mathrm{OH}$-group to that of Resveratrol: $\mathrm{p} K_{\mathrm{a}}\left(\mathrm{F}_{2}-\mathbf{4 2}\right)=12$. The synthesis could have been also started from acid $\mathbf{3 2}$.

Finally, in 2017, Measom, Hirst and colleagues replaced the central biphenyl moiety of Darapladib - an agent for the treatment of atherosclerosis, - with Ar-BCP motif (44, Scheme 9c). ${ }^{27 \mathrm{~d}}$ The obtained compound $\mathbf{4 4}$ was more water-soluble than Darapladib, but slightly less active. The synthesis of $\mathbf{4 4}$ was undertaken from acid $\mathbf{4 5}$ in three steps. Indeed, bioactive compounds with the biphenyl motif, like Darapladib, seem to be the most obvious targets for the incorporation of $\mathrm{Ar}-\mathrm{F}_{2}-$ BCP fragments described herein. For example, the synthesis of $\mathrm{F}_{2}-\mathbf{4 4}$ could have been realized from the corresponding acid 46.

\section{CONCLUSIONS}

Herein, we developed a practical synthesis of the previously unknown gem-difluorinated bicyclo[1.1.1]pentanes ( $\left.\mathrm{F}_{2}-\mathrm{BCP}\right)$. The key synthetic step was an addition of $: \mathrm{CF}_{2}$-carbene, generated in situ from $\mathrm{CF}_{3} \mathrm{TMS} / \mathrm{NaI}$ mixture, to aryl/vinylsubstituted bicyclo[1.1.0]butanes. The synthesis was optimized to obtain up to $7 \mathrm{~g}$ of the target compounds (acid 17) in one run. Experimental physico-chemical properties, acidity, basicity, lipophilicity and water solubility, - were measured for the obtained compounds. Based on this data, gem-difluorinated bicyclo[1.1.1]pentanes are suggested as novel saturated mimics for the benzene ring in medicinal chemistry projects.

The described herein synthetic approach gives access to mono- and bifunctional $\mathrm{F}_{2}$-BCPs. Starting from the corresponding aryl-substituted bicyclo[1.1.0]butane one could obtain Ar-substituted $\mathrm{F}_{2}$-BCPs, - like acid 17, amine 27, alcohol 28 (Schemes 6,7) - suitable for the replacement of biphenyl cores in bioactive compounds. On the other hand, acid 32 (Scheme 7) gives an access to a wide range of bifunctional compounds, - amino acids, diamines, amino alcohols, etc, - by stepwise standard modifications of the carboxylic groups. This work is currently in progress in our laboratory.

Also, the successful addition of : $\mathrm{CF}_{2}$-carbene to compound 9 (Table 1, Scheme 5) suggests that other carbenes of type : $\mathrm{CF}(\mathrm{R})$ might also be used. To prove this hypothesis, we also want to disclose our first results in this area: addition of : $\mathrm{CFCl}$-carbene to compound $\mathbf{9}$ under the basic conditions allowed to obtain $\mathrm{Cl}$,F-disubstituted acid $\mathbf{4 7}$ in $31 \%$ noneoptimized yield (Scheme 10).

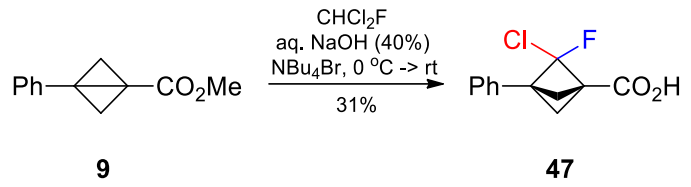

Scheme 10. Synthesis of Cl,F-acid 47 by an addition of : $\mathrm{CFCl}$-carbene to substrate $\mathbf{9}$.

We do believe that with the practical synthetic protocol in hand and appropriate physico-chemical properties, gemdifluorinated bicyclo[1.1.1]pentanes ( $\mathrm{F}_{2}$-BCPs) will find practical application in drug discovery projects very soon. ${ }^{34}$

\section{ASSOCIATED CONTENT}

\section{Supporting Information}

The Supporting Information is available free of charge on the website.

Copies of spectra, X-Ray and experimental lipophilicity and solubility data.

\section{AUTHOR INFORMATION}

\section{Corresponding Author}

*pavel.mykhailiuk@gmail.com, www.mykhailiukchem.org

\section{ACKNOWLEDGMENT}

We thank Prof. A. Tolmachev (Enamine) for financial support of this project, Dr. E. Rusanov (IOC) for X-Ray crystallographic analysis of acid 17, Dr. S. Shishkina for the help with analysis of CCDC database, Dr. D. Panov for the synthesis of model compounds 37-39, Mrs. I. Sadkova for the help with the preparation of the manuscript.

\section{REFERENCES}

1. Taylor, R. D.; MacCoss, M.; Lawson, A. D. G. Rings in Drugs. J. Med. Chem. 2014, 57, 5845-5859.

2. www.drugbank.ca

3. a) Lovering, F.; Bikker, J.; Humblet, C. Escape from Flatland: Increasing Saturation as an Approach to Improving Clinical Success. 
J. Med. Chem. 2009, 52, 6752-6756. b) Lovering, F. Escape from Flatland 2: complexity and promiscuity. Med. Chem. Commun. 2013, 4, 515-519.

4. Meanwell, N. A. Synopsis of Some Recent Tactical Application of Bioisosteres in Drug Design. J. Med. Chem. 2011, 54, 2529-2591.

5. Stepan, A. F.; Subramanyam, C.; Efremov, I. V.; Dutra, J. K.; O’Sullivan, T. J.; DiRico, K. J.; McDonald, W. S.; Won, A.; Dorff, P. H.; Nolan, C. E.; Becker, S. L.; Pustilnik, L. R.; Riddell, D. R.; Kauffman, G. W.; Kormos, B. L.; Zhang, L.; Lu, Y.; Capetta, S. H.; Green, M. E.; Karki, K.; Sibley E.; Atchison, K. P.; Hallgren, A. J.; Oborski, C. E.; Robshaw, A. E.; Sneed, B.; O’Donnell, C. J. Application of the Bicyclo[1.1.1]pentane Motif as a Nonclassical Phenyl Ring Bioisostere in the Design of a Potent and Orally Active $\gamma$-Secretase Inhibitor. J. Med. Chem. 2012, 55, 3414-3424.

6. For reviews, on the use of bicyclo[1.1.1]pentanes and related structures as saturated bioisosteres of benzene in medicinal chemistry, see: a) Mykhailiuk, P. K. Saturated bioisosteres of benzene: where to go next? Org. Biomol. Chem. 2019, 17, 2839-2849. b) Locke, G. M.; Bernhard, S. S. R.; Senge, M. O. Nonconjugated Hydrocarbons as Rigid-Linear Motifs: Isosteres for Material Sciences and Bioorganic and Medicinal Chemistry. Chem. Eur. J. 2019, 25, 4590-4647.

7. For some recent examples, see: a) Gianatassio, R.; Lopchuk, J. M.; Wang, J.; Pan, C.-M.; Malins, L. R.; Prieto, L.; Brandt, T. A.; Collins, M. R.; Gallego, G. M.; Sach, N. W.; Spangler, J. E.; Zhu, H.; Zhu, J.; Baran, P. S. Science, 2016, 351, 241-246. b) Kanazawa, J.; Maeda, K.; Uchiyama, M. Radical Multicomponent Carboamination of [1.1.1]Propellane. J. Am. Chem. Soc. 2017, 139, 17791-17794. c) Caputo, D. F. J.; Arroniz, C.; Dürr, A. B.; Mousseau, J. J.; Stepan, A. F.; Mansfield, S. J.; Anderson, E. A. Synthesis and applications of highly functionalized 1-halo-3-substituted bicyclo[1.1.1]pentanes. Chem. Sci. 2018, 9, 5295. d) Shelp, R. A.; Walsh, P. J. Synthesis of BCP Benzylamines From 2-Azaallyl Anions and [1.1.1]Propellane. Angew. Chem. Int. Ed. 2018, 57, 15857-15861. e) Makarov, I. S.; Brocklehurst, C. E.; Karaghiosoff, K.; Koch, G.; Knochel, P. Synthesis of Bicyclo[1.1.1]pentane Bioisosteres of Internal Alkynes and para-Disubstituted Benzenes from [1.1.1]Propellane. Angew. Chem. Int. Ed. 2017, 56, 12774-12777. f) Lopchuk, J. M.; Fjelbye, K.; Kawamata, Y.; Malins, L. R.; Pan, C.-M.; Gianatassio, R.; Wang, J.; Prieto, L.; Bradow, J.; Brandt, T. A.; Collins, M. R.; Elleraas, J.; Ewanicki, J.; Farrell, W.; Fadeyi, O. O.; Gallego, G. M.; Mousseau, J. J.; Oliver, R.; Sach, N. W.; Smith, J. K.; Spangler, J. E.; Zhu, H.; Zhu, J.; Baran, P. S. Strain-release heteroatom functionalization: development, scope, and stereospecificity. Strain-Release Heteroatom Functionalization: Development, Scope, and Stereospecificity. J. Am. Chem. Soc. 2017, 139, 3209-3226. g) Wong, M. L. J.; Mousseau, J. J.; Mansfield, S. J.; Anderson, E. A. Synthesis of enantioenriched $\alpha$-chiral bicyclo[1.1.1]pentanes. Org. Lett. 2019, 21, 2408-2411.

8. For a recent review on the chemistry of bicyclo[1.1.1]pentanes, see: Kanazawa, J.; Uchiyama, M. Recent Advances in the Synthetic Chemistry of Bicyclo[1.1.1]pentane. Synlett 2019, 30, 1-11.

9. Our contribution to the field: a) Kokhan, S. O.; Tymtsunik, A. V.; Grage, S. L.; Afonin, S.; Babii, O.; Berditsch, M.; Strizhak, A. V.; Bandak, D.; Platonov, M. O.; Komarov, I. V.; Ulrich, A. S.; Mykhailiuk, P. K. Design, Synthesis, and Application of an Optimized Monofluorinated Aliphatic Label for Peptide Studies by Solid-State ${ }^{19}$ F NMR Spectroscopy. Angew. Chem. Int. Ed. 2016, 55, 14788-14792. b) Mykhailiuk, P. K.; Voievoda, N. M.; Afonin, S.; Ulrich, A. S.; Komarov, I. V. An optimized protocol for the multigram synthesis of 3-(trifluoromethyl)bicyclo[1.1.1]pent-1ylglycine $\left(\mathrm{CF}_{3}-\mathrm{Bpg}\right)$. J. Fluorine Chem. 2010, 131, 217-220. c) Mikhailiuk, P. K.; Afonin, S.; Chernega, A. N.; Rusanov, E. B.; Platonov, M. O.; Dubinina, G. G.; Berditsch, M.; Ulrich, A. S.; Komarov, I. V. Conformationally Rigid Trifluoromethyl-Substituted $\alpha$-Amino Acid Designed for Peptide Structure Analysis by Solid-State ${ }^{19}$ F NMR Spectroscopy. Angew. Chem. Int. Ed. 2006, 45, 5659-5661.

10. a) Klopsch, R.; Schliiter, A.-D. A [1.1.1]propellane with an unprotected hydroxy group in the side chain. Tetrahedron 1995, 51, 10491-10496. b) Freudenberger, R.; Lamer, W.; Schlüter, A.-D. A [1.1.1]propellane with a protected functional group in the side chain and its homopolymer. J. Org. Chem. 1993, 58, 6497-6498. c) Werner, M.; Stephenson, D. S.; Szeimies, G. Synthesis of 1.1.1.Propellanes by Bridging ofBicyclo[1.1.0]butanes. Liebigs Ann. 1996, 1705-1715.

11. Hamrock, S. J.; Michl, J. 2,2-Dichloro[1.1.1]propellane. J. Org. Chem. 1992, 57, 5027-5031.

12. a) Wiberg, K. B.; Ross, B. S.; Isbell, J. J.; McMurdie, N. 2Substituted bicyclo[1.1.1]pentanes. J. Org. Chem. 1993, 58, 13721376. b) Wiberg, K. B.; Williams, V. Z. Bicyclo[1.1.1]pentane derivatives. J. Org. Chem. 1970, 35, 369-373. c) Kaleta, J.; Rončević, I.; Císařová, I.; Dračínský, M.; Šolínová, V.; Kašička, V.; Michl, J. Bridge-Chlorinated Bicyclo[1.1.1]pentane-1,3-dicarboxylic Acids. J. Org. Chem. 2019, 84, 2448-2461. d) Levin, M. D.; Kaszynski, P.; Michl, J. Bicyclo[1.1.1]pentanes, [n]Staffanes, [1.1.1]Propellanes, and Tricyclo[2.1.0.0 $\left.{ }^{2,5}\right]$ pentanes. Chem. Rev. 2000, 100, 169-234.

13. Zhu, Q.; Ji, D.; Liang, T.; Wang, X.; Xu, Y. Efficient PalladiumCatalyzed $\mathrm{C}-\mathrm{H}$ Fluorination of $\mathrm{C}\left(\mathrm{sp}^{3}\right)-\mathrm{H}$ Bonds: Synthesis of $\beta$ Fluorinated Carboxylic Acids. Org. Lett. 2015, 17, 3798-3801.

14. Hutskalova, V.; Mykhailiuk, P. K. Pd-Catalyzed directed CH(hetero)arylation of cyclic $\alpha$-amino acids: effects of substituents and the ring size. Org. Biomol. Chem. 2019, 17, 4342-4349.

15. Larrosa, M.; Heiles, S.; Becker, J.; Spengler, B.; Hrdina, R. C-H Bond Arylation of Diamondoids Catalyzed by Palladium(II) Acetate. Adv. Synth. Catal. 2016, 358, 2163-2171.

16. Zaitsev, V. G.; Shabashov, D.; Daugulis, O. Highly Regioselective Arylation of $\mathrm{sp}^{3} \mathrm{C}-\mathrm{H}$ Bonds Catalyzed by Palladium Acetate. J. Am. Chem. Soc. 2005, 127, 13154-13155.

17. Robinson, R.; Michl, J. Chlorination of bicyclo[1.1.1]pentane derivatives. J. Org. Chem. 1989, 54, 2051-2053.

18. Levin, M. D.; Hamrock, S. J.; Kaszynski, P.; Shtarev, A. B.; Levina, G. A.; Noll, B. C.; Ashley, M. E.; Newmark, R.; Moore, G. G.; Michl, J. Preparation, Structure, and Properties of Symmetrically 1,3-Difunctionalized Penta- and Hexafluorobicyclo[1.1.1]pentanes. $J$. Am. Chem. Soc. 1997, 119, 12750-12761.

19. Takahira, Y.; Chen, M.; Kawamata, Y.; Mykhailiuk, P.; Nakamura, H.; Peters, B. K.; Reisberg, S. H.; Li, C.; Chen, L.; Hoshikawa, T.; Shibuguchi, T.; Baran, P. S. Electrochemical C( $\left.\mathrm{sp}^{3}\right)$ H Fluorination. Synlett 2019, 30, 1178-1182.

20. a) Hall, H. K.; Smith, C. D.; Blanchard, E. P.; Cherkofsky, S. C.; Sieja J. B. Synthesis and polymerization of bridgehead-substituted bicyclobutanes. J. Am. Chem. Soc.1971, 93, 121-130. b) Applequist, D. E.; Renken, T. L.; Wheeler, J. W. Polar substituent effects in 1,3disubstituted bicyclo[1.1.1]pentanes. J. Org. Chem. 1982, 47, 49854995. c) Measom, N. D.; Down, K. D.; Hirst, D. J.; Jamieson, C.; Manas, E. S.; Patel, V. K.; Somers, D. O. Investigation of a Bicyclo[1.1.1]pentane as a Phenyl Replacement within an LpPLA Inhibitor. ACS Med. Chem. Lett. 2017, 8, 43-48. 
21. Wan, Z.; Zhang, X.; Wang, J.; Sender, M.; Manas, E. S.; Rivero, R. A.; Pero, J. E.; Neipp, C. E.; Patel, V. K. WO2016/011930 A1.

22. a) Kubyshkin, V. S.; Mykhailiuk, P. K.; Afonin, S.; Ulrich, A. S.; Komarov, I. V. Incorporation of cis- and trans-4,5Difluoromethanoprolines into Polypeptides. Org. Lett. 2012, 14, 5254-5257. b) Kubyshkin, V. S.; Mykhailiuk, P. K.; Afonin, S.; Grage, S. L.; Komarov, I. V.; Ulrich, A. S. Incorporation of labile trans-4,5-difluoromethanoproline into a peptide as a stable label for 19F NMR structure analysis. J. Fluorine Chem. 2013, 152, 136-143. c) Kubyshkin, V.; Kheylik, Y.; Mykhailiuk, P. K. Synthesis and studies on gem-fluorinated 2-azabicyclo[n.1.0]alkanes. J. Fluorine Chem. 2015, 175, 73-83.

23. a) Wang, F.; Luo, T.; Hu, J.; Wang, Y.; Krishnan, H. S.; Jog, P. V.; Ganesh, S. K.; Prakash, G. K. S.; Olah, G. A. Synthesis of gemDifluorinated Cyclopropanes and Cyclopropenes: Trifluoromethyltrimethylsilane as a Difluorocarbene Source. Angew. Chem. Int. Ed. 2011, 50, 7153-7157. b) Bychek, R. M.; Levterov, V. V.; Sadkova, I. V.; Tolmachev, A. A.; Mykhailiuk, P. K. Synthesis of Functionalized Difluorocyclopropanes: Unique Building Blocks for Drug Discovery. Chem. Eur. J. 2018, 24, 12291-12297.

24. a) Doering, W. von E.; Coburn, J. F.; 1, 3dimethylbicyclo[1.1.0]butane. Tetrahedron Lett. 1965, 15, 991-995. b) Wiberg, K. B.; Lampman, G. M.; Ciula, R. P.; Connor, D. S.; Schertner, P.; Lavanish, J. Bicyclo[1.1.0]butane. Tetrahedron 1965, 21, 2749-2769.

25. Wipf, P.; Stephenson, C. R. J.; Okumura, K. Transition-MetalMediated Cascade Reactions: C,C-Dicyclopropylmethylamines by Way of Double C,C-б-Bond Insertion into Bicyclobutanes. J. Am. Chem. Soc. 2003, 125, 14694-14695.

26. X-Ray crystal data - cif. file, - for compound $\mathbf{1 7}$ has been deposited online to the Cambridge Crystallographic Data Centre under the number CCDC 1922933 via www.ccdc.cam.ac.uk

27. a) Nicolaou, K. C.; Vourloumis, D.; Totokotsopoulos, S.; Papakyriakou, A.; Karsunky, H.; Fernando, H.; Gavrilyuk, J.; Webb, D.; Stepan, A. F. Synthesis and Biopharmaceutical Evaluation of Imatinib Analogues Featuring Unusual Structural Motifs. ChemMedChem, 2016, 11, 31-37. b) Thirumoorthi, N. T.; Adsool, V. A. A practical metal-free homolytic aromatic alkylation protocol for the synthesis of 3-(pyrazin-2-yl)bicyclo[1.1.1]pentane-1-carboxylic acid. Org. Biomol. Chem. 2016, 14, 9485-9489. c) Goh, Y. L.; Cui, Y. T.; Pendharkar, V.; Adsool, V. A. Toward Resolving the Resveratrol Conundrum: Synthesis and in Vivo Pharmacokinetic Evaluation of BCP-Resveratrol. ACS Med. Chem. Lett. 2017, 8, 516-520. d) Measom, N. D.; Down, K. D.; Hirst, D. J.; Jamieson, C.; Manas, E. S.; Patel, V. K.; Somers, D. O. Investigation of a Bicyclo[1.1.1]pentane as a Phenyl Replacement within an LpPLA 2 Inhibitor. ACS Med. Chem. Lett., 2017, 8, 43-48.

28. Reissig, H.-U.; Zimmer, R. Thrilling strain! Donor-acceptorsubstituted cyclobutanes for the synthesis of (hetero)cyclic compounds Angew. Chem. Int. Ed. 2015, 54, 5009-5011.

29. Skibinski, M.; Wang, Y.; Slawin, A. M. Z.; Lebl, T.; Kirsch, P.; O'Hagan, D. Alicyclic Ring Structure: Conformational Influence of the $\mathrm{CF}_{2}$ Group in Cyclododecanes. Angew. Chem. Int. Ed. 2011, 50, 10581-10584.

30. Compounds 34 (CCDC 116257) and 35 (116256) and their X-Ray crystal data are reported in: Rehm, J. D. D.; Ziemer, B.; Szeimies, G. A Facile Route to Bridgehead Disubstituted Bicyclo[1.1.1]pentanes Involving Palladium-Catalyzed Cross-Coupling Reactions. Eur. J. Org. Chem. 1999, 2079-2085.
31. For selected reviews on the impact of fluorine atom(s) on the physico-chemical properties, and the use of fluoroorganic compounds in drug design, see: (a) Hagmann, W. K. The many roles for fluorine in medicinal chemistry. J. Med. Chem. 2008, 51, 4359-4369. b) Müller, K.; Faeh, C.; Diederich, F. Fluorine in pharmaceuticals: looking beyond intuition Science 2007, 317, 1881-1886. c) Meanwell, N. A. Fluorine and fluorinated motifs in the design and application of bioisosteres for drug design J. Med. Chem. 2018, 61, 5822-5880.

32. Auberson, Y. P.; Brocklehurst, C.; Furegati, M.; Fessard, T. C.; Koch, G.; Decker, A.; La Vecchia, L.; Briard, E. Improving Nonspecific Binding and Solubility: Bicycloalkyl Groups and Cubanes as para-Phenyl Bioisosteres. ChemMedChem 2017, 12, 590598.

33. (a) Olsen, J. A.; Banner, D. W.; Seiler, P.; Sander, U. O.; D’Arcy, A.; Stihle, M.; Müller, K.; Diederich, F. A fluorine scan of thrombin inhibitors to map the fluorophilicity/fluorophobicity of an enzyme active site: evidence for $\mathrm{C}-\mathrm{F} \cdots \mathrm{C}=\mathrm{O}$ interactions. Angew. Chem., Int. Ed. 2003, 42, 2507-2511. (b) Olsen, J. A.; Banner, D. W.; Seiler, P.; Wagner, B.; Tschopp, T.; Obst-Sander, U.; Kansy, M.; Müller, K.; Diederich, F. Fluorine interactions at the thrombin active site: protein backbone fragments $\mathrm{H}-\mathrm{C} \alpha-\mathrm{C}=\mathrm{O}$ comprise a favorable $\mathrm{C}-\mathrm{F}$ environment and interactions of $\mathrm{C}-\mathrm{F}$ with electrophiles. ChemBioChem 2004, 5, 666-675. (c) Hof, F.; Scofield, D. M.; Schweizer, W. B.; Diederich, F. A weak attractive interaction between organic fluorine and an amide group. Angew. Chem., Int. Ed. 2004, 43, 5056-5059.

34. 11 July 2019, a manuscript by Merck chemists on a related topic appeared online. The authors obtained aryl-substituted $\mathrm{F}_{2}$-BCPs from aryl-substituted bicyclo[1.1.0]butanes and $\mathrm{FSO}_{2} \mathrm{CF}_{2} \mathrm{CO}_{2} \mathrm{TMS}$ as a source of : $\mathrm{CF}_{2}$-carbene: Ma, X.; Sloman, D. L.; Han, Y.; Bennett, D. J. A selective synthesis of 2,2-difluorobicyclo[1.1.1]pentane analogues: "BCP-F2" Org. Lett. 2019, asap, DOI: 10.1021/acs.orglett.9b02026. 